\title{
ADSORPTION OF HALOTHANE VAPOUR IN GLASS SYRINGES*
}

\author{
R. Herchl, Ph.D. $\uparrow$
}

The Most common tool in medical research is the glass syringe. It is often employed for the sampling of various gases, vapours, and their mixtures. During our experiments regarding reproducibility of anaesthetic vapour-gas mixtures, we found that the results depended considerably upon the time the mixture remained in the syringe before analysis. After considering and eliminating other possible causes, it seemed the adsorption on the ground glass wall was responsible. The adsorption in the syringe occurred when it contained an anaesthetic vapour, not pure air or other gases. For our study we used halothane vapour-air mixtures.

\section{METHOD}

For each experiment we use a clean and desorbed syringe. After flling it with a halothane vapour-air mixture, the pressure is adjusted to one atmosphere. Due to adsorption of the vapour on the ground glass wall, the pressure in the syringe

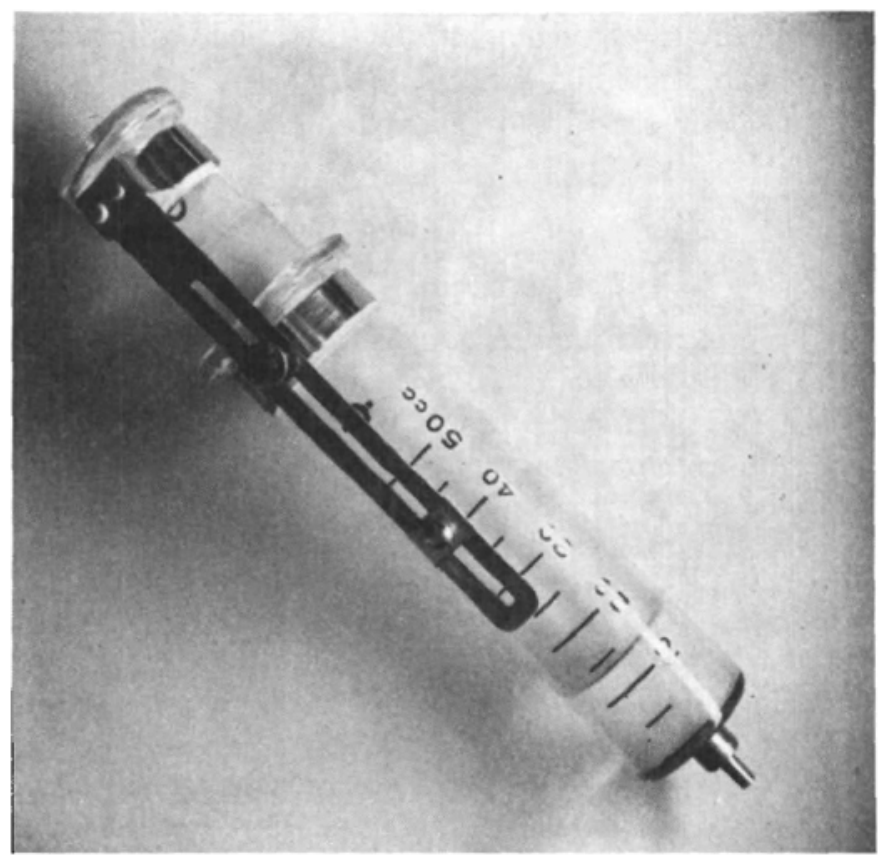

Figune 1. Manifold for adsorption study in a glass syringe.

'This work has been supported by a grant from The Canadian Foundation for the Advancement of Therapeutics.

fAssociate Professor, Department of Anaesthesia, University of Manitoba, Winnipeg.

Can. Anaes. Soc. J., vol. 17, no. 6, November 1970 
changes with time. From these pressure changes we can calculate the volume of the adsorbed vapour and thus the change in vapour concentration in a given time.

\section{Apparatus}

The system (Figure 1) consists of a metal manifold and standard three-way valves (B-D stopcocks). At one end of the system is attached a sampling syringe containing vapour-air mixture to be studied. ${ }^{1}$ Between valves 1 and 2 , a volume adjustable syringe for the adsorption study is joined to the manifold. Teflon tubing connects a sensitive pressure gauge to the other end of the system (Portable Airflow Testing Set, Mark 1, Airflow Developments Ltd., England).

\section{Procedure}

Prepared halothane vapour-air mixture from the sampling syringe is withdrawn through valve 2 (Figure 1) into the syringe for adsorption study. Valve 1 is then opened, connecting the sensitive pressure gauge to the system. By adjusting the plunger of the sampling syringe, a pressure of one atmosphere is obtained in the system. Then the sampling syringe is disconnected from the system by closing valve 2 . The described procedure takes about 35 seconds. From then on, readings of the changes in the pressure of the system are taken each minute for a quarter of an hour. Time is measured by a stopwatch. Temperature of adsorption is at stable temperature $\left(24^{\circ} \mathrm{C}\right.$ to $\left.25^{\circ} \mathrm{C}\right)$.

\section{ResUlts}

In Figure 2, adsorption curves in a syringe can be seen; these curves represent pressure changes for various concentrations, plotted against time.

The pressure in a syringe filled with pure air does not change with time. Therefore, when adsorption occurs in the syringe filled with a halothane vapour-air mixture, only halothane vapour is adsorbed on the ground glass wall. Then from a known volume of the mixture originally at $760 \mathrm{~mm} \mathrm{Hg}$, a relative change in concentration can be calculated from decreased pressure in the syringe after a certain time interval. At room temperature and low pressure we may consider the mixture behaving as an ideal gas. As an example of the calculation, let us consider a mixture of 0.9 volume per cent (vol. per cent) of halothane vapour in air at $760 \mathrm{~mm} \mathrm{Hg}$ in a $200 \mathrm{ml}$ syringe. The volume of pure halothane vapour in the mixture is $1.8 \mathrm{ml}^{2}$ After 5 minutes of adsorption, the pressure in the syringe decreases $0.42 \mathrm{~mm} \mathrm{Hg}$. Thus the pressure is $759.58 \mathrm{~mm} \mathrm{Hg}$ which means the volume of the mixture would actually be $199.88 \mathrm{ml}$ at $760 \mathrm{~mm} \mathrm{Hg}$ pressure. The difference from the original volume of $200 \mathrm{ml}$ is $0.12 \mathrm{ml}$. It represents the volume of halothane vapour adsorbed on the syringe wall. After adsorbing, the mixture in the syringe contains only $1.68 \mathrm{ml}$ of pure halothane vapour at a concentration of 0.84 vol. per cent. Comparing with the original concentration 0.9 vol. per cent, the change of $0.06 \mathrm{vol}$. per cent represents a relative decrease in concentration of 6.11 per cent.

Employing this method, the figures in the Table were calculated. These show 


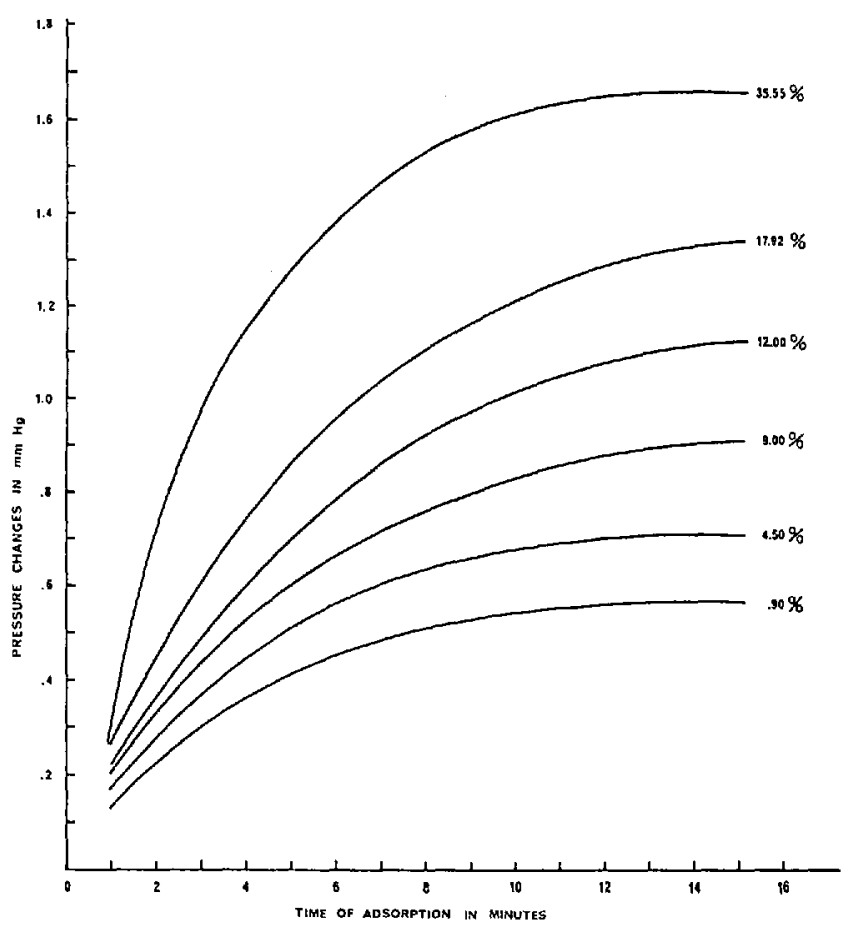

Figure 2. Pressure changes in a syringe with time due to adsorption of halothane from gaseous mixtures.

how various concentrations of halothane vapour in air decrease in syringes, due to adsorption, after 5,10 , and 15 minutes.

The curves in Figure 3 now demonstrate clearly that a lower concentration of halothane in a gaseous mixture shows very large relative decrease in concentration.

TABLE II

Relative Change in Halothane Content due to Adsorptron

\begin{tabular}{cccc}
\hline \hline & \multicolumn{2}{c}{$\begin{array}{c}\text { Relative change in concentration of } \\
\text { halothane due to adsorption after }\end{array}$} \\
\cline { 2 - 4 } $\begin{array}{c}\text { Original concentration of } \\
\text { halothane in syringe } \\
\%\end{array}$ & $\begin{array}{c}5 \text { minutes } \\
\%\end{array}$ & 10 minutes & 15 minutes \\
$\%$ & 0.47 & 0.60 & 0.61 \\
\hline 35.55 & 0.52 & 0.74 & 0.82 \\
17.92 & 0.69 & 0.98 & 1.09 \\
12.00 & 0.80 & 1.12 & 1.21 \\
9.00 & 1.44 & 1.89 & 2.00 \\
4.50 & 6.11 & 7.89 & 8.22 \\
0.90 & & & \\
\hline
\end{tabular}

\section{DisCUSSION}

The experiments were carried out with syringes from the same manufacturer. Surfaces of their ground glass walls were degreased and cleaned carefully. In spite of these precautions, and under the same experimental conditions, the 


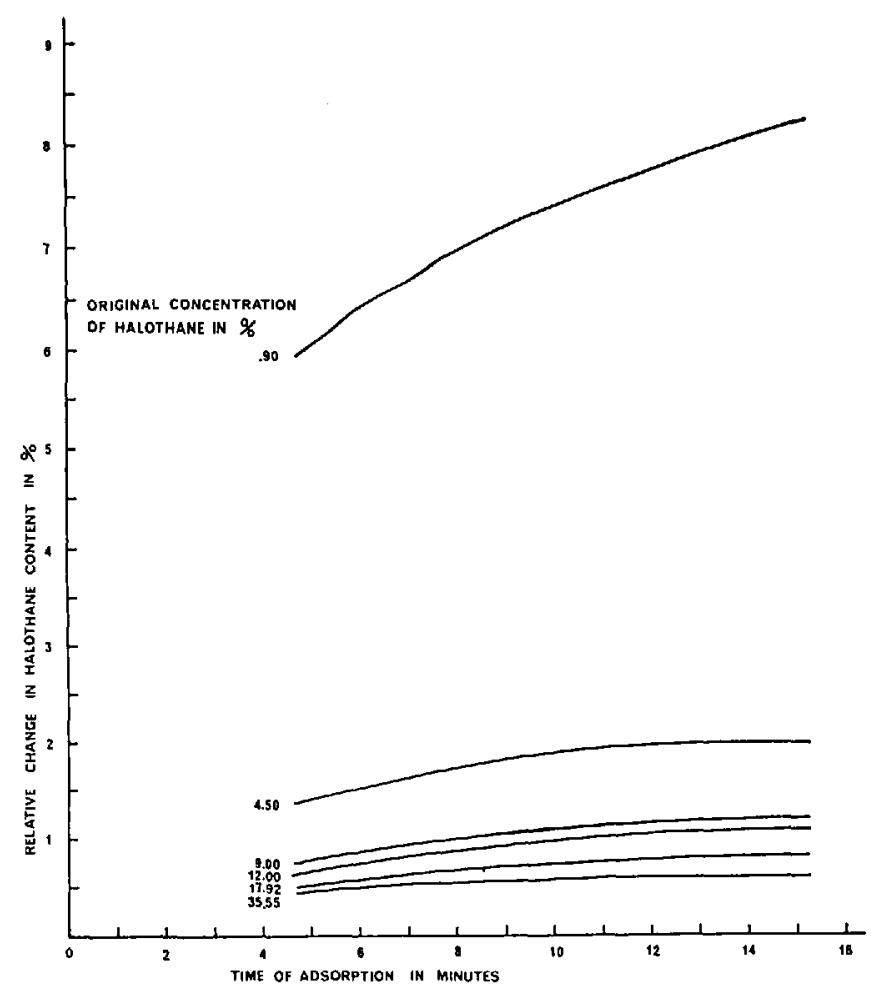

Figure 3. Relative decrease of halothane content due to adsorption in a syringe with time for various halothane mixtures.

adsorption varied in different syringes as much as \pm 10 per cent. Therefore, we have chosen one syringe which was representative of average adsorption values and used it for all experiments. Before each adsorption study, the syringe was allowed to "desorbe" for about one hour. The plunger was withdrawn and for the sake of speeding up the process, clean air from a tank was drawn into the syringe and pushed out from time to time.

Calculated changes in concentrations were compared with a direct analysis of the studied mixture, analyzed by an interferometer. The difference between the original concentration of the mixture and final concentration after 15 minutes of an experiment measured by the interferometer, was shown to be between $2-6$ per cent lower in concentration than results predicted by calculation. The discrepancy was probably caused by the 35 seconds required for pressure adjustment. During the time the system was being adjusted to $760 \mathrm{~mm} \mathrm{Hg}$ understandably it did not record pressure changes due to adsorption. Because of this factor the beginning of the adsorption process was hard to measure, and the 35 seconds was just the time during which the most rapid adsorption occurred. Therefore, the figures for our results indicating decreases in concentration should be lower than they actually were but they did, of course, give us the idea of taking the adsorption in syringes into account during our experimental programme. 


\section{SUMMARY}

The adsorption of halothane vapour on the ground-glass in all-glass syringes was studied. We devised a method to estimate adsorption by measuring changes of pressure in syringes filled with halothane vapour-air mixtures. The amount of adsorption of the halothane vapour by ground-glass was considerable, particularly at lower concentrations of the mixture. This factor significantly affects accuracy in the particular estimation of anaesthetic vapour-gas mixtures.

\section{RÉSUMÉ}

Nous avons étudié l'adsorption de vapeur d'halothane sur la "base-verre" dans des seringues toutes de verre. Nous avons mis à point une méthode pour déterminer l'adsorption en mesurant les changements de pression dans des seringues remplies de mélanges de vapeur d'halothane-air. La quantité d'adsorption de vapeur d'halothane par la "base-verre" était considérable, particulièrement aux plus basses concentrations du mélange. Ce facteur modifie de façon significative la précision dans l'évaluation particulière des mélanges vapeurs anesthésiques-gaz.

\section{REFERENCES}

1. Herche, R. The Preparation of Accurate Standard Mixtures of Inhalation Anaesthetic Agents. (To be published.)

2. HILI, D. W. Physics Applied to Anaesthesia. Brit. J. Anaes. 38: 476 (1966). 